\title{
Lealdade aos meios de hospedagem: um estudo com turistas de pousadas de Angra dos Reis (Rio de Janeiro, Brasil)
}

\section{Hospitality loyalty: a study with hostels tourists in Angra dos Reis (Rio de Janeiro, Brazil)}

\author{
Márcio Moutinho Abdalla (ABDALLA, M. M.) \\ Joyce Gonçalves Altaf (ALTAF, J. G.) ${ }^{* * *}$ \\ Irene Raguenet Troccoli (TROCCOLI, I. R.) ${ }^{* * *}$ \\ Karine Weibel Pinto Nóbrega (NÓBREGA, K. W. P.) ${ }^{* * * *}$ \\ Gilmar Francisco da Cruz (CRUZ, G. F. da)
}

\begin{abstract}
RESUMO - Esta pesquisa quali-quantitativa realizada em 2009 enfocou-se na avaliação das respostas fornecidas por turistas brasileiros que estavam hospedados em pousadas no município fluminense de Angra dos Reis (Rio de Janeiro, Brasil). Por meio de entrevistas diretas e padronizadas e de questionários estruturados, verificaram-se as percepções dos turistas sobre o risco embutido na escolha, o preço pago pelo serviço, a qualidade do serviço, a satisfação para com o serviço recebido e a lealdade daí derivada. Das oito hipóteses propostas, referentes às variáveis preditoras da intenção de lealdade, apenas quatro foram aceitas: a infraestrutura da pousada, o tempo de check in, a predisposição a recomendar o local, e o comprometimento do hóspede para com a
\end{abstract}

\footnotetext{
* Graduação em Administração pela Faculdade de Ciências Contábeis e Administrativas Machado Sobrinho (FCCAMS), Especialização em Controladoria e Finanças pela Universidade Federal de Lavras (UFLA), Mestrado em Administração e Desenvolvimento Empresarial (MADE-UNESA), Doutorando em Administração pela Fundação Getúlio Vargas (FGV/EBAPE). Professor da Universidade Federal Fluminense, Instituto de Ciências Humanas e Sociais (UFF/ICHS). Endereço para correspondência: Rua Desembargador Ellis Hermídio Figueira, 783, bloco A, sala 304. CEP 27213-415 - Volta Redonda - Rio de Janeiro (Brasil). Fone (24) 3076-0887. E-mail: marciomabdalla@gmail.com
}

\footnotetext{
** Graduação em Serviço Social pela Universidade Federal de Juiz de Fora (UFJF) e em Administração de Empresas pela Faculdade Metodista Grambery, Especialização em história econômica pela UFJF, Mestrado em Administração e Desenvolvimento Empresarial (MADE-UNESA). Professora do Instituto Vianna Júnior, Faculdade de Administração de Empresas. Endereço para correspondência: Av. dos Andradas, 415. CEP 36036-000 Juiz de Fora - Minas Gerais (Brasil). Fone (32) 3239-2940. E-mail: jgaltaf@yahoo.com.br
}

\footnotetext{
*** Graduação em Ciências Econômicas pela Universidade Federal do Rio de Janeiro (UFRJ), Mestrado e Doutorado em Administração de Empresas pela Pontifícia Universidade Católica do Rio de Janeiro (PUC Rio). Professora do Mestrado em Administração e Desenvolvimento Empresarial (MADE) da Universidade Estácio de Sá. Endereço para correspondência: Av. Presidente Vargas, 642/22 andar. CEP 20071-001 - Rio de Janeiro - Rio de Janeiro (Brasil). Fone (21) 2206-9890. E-mail: irene.troccoli@estacio.br.

Graduação em Administração pela Uniabeu Centro Universitário. Empresária. Endereço para correspondência: Rua Desembargador Ellis Hermídio Figueira, 783, bloco A, sala 304. CEP 27213-415 Volta Redonda - Rio de Janeiro (Brasil). Fone (24) 3076-0887. E-mail: callegari.weibel@ oi.com.br.

Graduação em Administração pela Uniabeu Centro Universitário, concluinte em Especialização do curso Gerenciamento de Projetos-Visão PMI pela Universidade Estácio de Sá e Graduando em Tecnologia de Sistemas de Computação pela Universidade Federal Fluminense (UFF). Endereço para correspondência: Rua Salomão Reseck, 469, Morro do Carmo. CEP 23903-125 - Angra dos Reis - Rio de Janeiro (Brasil). Fone: 24-9920-5590. E-mail: gilmarvicosa@ hotmail.com
} 
organização. Verificou-se que o preço não foi fator preponderante no tocante à intenção de lealdade, sugerindo que clientes leais estão dispostos a pagar preços premium pelos serviços de seus interesses. Confirmou-se que o bom atendimento prediz as intenções de lealdade, embora, neste caso, possa ter sido confundido com impessoalidade, podendo ter interferido nos resultados. Verificou-se que o julgamento das expectativas em relação ao grau de satisfação não exerce poder preditivo frente à intenção de lealdade do turista. Por fim, estabelecem-se recomendações aos atores envolvidos no estudo, especialmente as organizações, e destacam-se as limitações do trabalho.

Palavras-chave: Pousadas; Intenção de Lealdade; Angra dos Reis; Marketing de Serviços.

ABSTRACT - This quantitative-qualitative research focused on assessing the responses provided by domestic tourists who stayed in hostels in Angra dos Reis, Rio de Janeiro State, Brazil. Through direct interviews and standardized structured questionnaires, the tourists' perceptions were observed concerning the risk embedded in the choice, the price paid for the service, the quality of service, the satisfaction with the service received and loyalty derived. From the eight hypotheses proposed, referring to the predictor variables of loyalty intention, only four were accepted: the hostel infrastructure, check in duration, the willingness to recommend the place, and guest commitment to the organization. It was found that price is not a major factor in terms of loyalty intention, which suggests that loyal customers are willing to pay premium prices for the services that they want. It was confirmed that proper care predicts loyalty intentions, although in this case this may have been confused with neutrality, which may have affected the results. It was found that expectations regarding the level of satisfaction have no predictive power as for the tourist loyalty intentions. Finally, recommendations are placed for the actors involved in the study, especially the organizations, and the limitations of this research are highlighted.

Key words: Hostels; Loyalty Intentions; Angra dos Reis; Marketing service 


\section{INTRODUÇÃO}

Os consumidores leais estão além da satisfação e até mesmo da preferência duradoura por uma marca ou por um tipo de serviço. Esses consumidores são defensores determinados da marca ou do serviço mesmo em situações em que as contraofertas dos concorrentes tentam seduzi-los (MOWEN; MINOR, 2008). Dentre outros, os pressupostos teóricos apontam, como potenciais antecedentes da lealdade, o risco percebido pelo cliente, o preço praticado, a qualidade percebida e a satisfação (HAWKINS, MOTHERSBAUGH，BEST，2007; SCHIFFMAN，KANUK，2000; FITZSIMMONS, FITZSIMMONS, 2005; GRÖNROOS, 2004; MOWEN, MINOR, 2008). Diante disso, na última década as organizações relacionadas ao turismo vêm ampliando sua consciência frente às grandes vantagens em se manter uma base sólida de clientes leais (LOUREIRO; GONZÁLEZ, 2008). Todavia, estudos que relacionem tal variável à atividade turística são escassos, especialmente aqueles com lastro quantitativo.

Apesar de a lealdade ser uma área ampla e extensa que engloba praticamente todo o campo do comportamento do consumidor, esta pesquisa, realizada no ano de 2009 como parte de um estudo maior concluído dois anos após, avaliou as percepções de turistas brasileiros sobre as pousadas da cidade fluminense de Angra dos Reis excluindo-se a área da Ilha Grande - em que se hospedaram. Dessa maneira, objetivouse relacionar as possíveis variáveis preditoras da lealdade dos turistas a este serviço e verificar qual ou quais dela(s) de fato apresentavam maior significância.

Para tanto, o trabalho foi dividido em três etapas. Inicialmente realizou-se pesquisa qualitativa composta de revisão bibliográfica sobre os tópicos abordados, assim como de pesquisa de campo com base em entrevistas. Posteriormente realizou-se pesquisa com abordagem quantitativa, que postula a existência de uma realidade externa a ser examinada com objetividade, por meio do uso de regressão logística binária. Finalmente, também se buscaram verificar, por meio de entrevistas diretas e padronizadas e de questionários estruturados, os riscos percebidos pelo turista no ramo de hospedagem no que tange a preço, qualidade, satisfação e lealdade. 


\section{FUNDAMENTAÇÃO TEÓRICA}

Este tópico tem, por objetivo, dissertar sobre os conceitos empregados na pesquisa, articulando-os teoricamente. Em especial, busca-se tratar dos cinco construtos teóricos empregados: risco percebido, preço, qualidade do serviço, satisfação para com o serviço recebido, e a lealdade daí derivada.

\subsection{RISCO PERCEBIDO}

Para Hawkins, Mothersbaugh e Best (2007), o risco percebido é uma função do indivíduo, do produto e da situação. Porém, alguns produtos e serviços geralmente são vistos como mais arriscados que outros. De acordo com Farias e Kovacs (2006), o indivíduo investe tempo, e às vezes dinheiro e esforço físico, na tentativa de minimizar os riscos percebidos, pelas várias estratégias de redução do risco. Ainda segundo os autores, dentre outras, estas estratégias podem remeter ao chamado menor risco manipulado, quando se trata de compra em determinados estabelecimentos. Por exemplo, mesmo que um consumidor perceba um alto grau de risco para as compras realizadas na Internet, ele pode perceber menor risco manipulado para a aquisição de produtos e serviços em determinadas lojas virtuais.

Para Sheth, Mittal e Newman (2001), o risco percebido das inovações refere-se à incerteza quanto à sua vantagem relativa concretizar-se ou não, e quanto à ocorrência ou não de um prejuízo previsto. Para Schiffman e Kanuk (2000), os consumidores devem constantemente tomar decisões acerca de quais produtos ou serviços comprar e onde comprá-los. Partindo-se do pressuposto de que os resultados e as consequências dessas decisões são frequentemente incertos, o consumidor percebe algum grau de risco ao tomar uma decisão de compra. Esta definição salienta duas dimensões relevantes de risco percebido: incerteza e consequências (HAWKINS; MOTHERSBAUGH; BEST, 2007).

Para Pereira e Cobra (2006), compradores frequentemente enfrentam o dilema de querer comprar um produto, mas muitas vezes hesitam em fazê-lo porque isto envolve assumir o risco de sofrer algum tipo de perda. Quando confrontado com este dilema, o consumidor se depara com uma variedade de estratégias que podem ser 
utilizadas para reduzir o risco de perda. O consumidor poderia, por exemplo, confiar no sucesso anterior na compra de uma determinada marca, procurar por conselhos de amigos, ou testar uma amostra grátis. Desta forma, o potencial comprador pode estar tão incerto quanto à melhor forma de reduzir risco quanto de realizar a compra.

\subsection{PREÇO}

Para Middleton (2002), os modelos econômicos clássicos de comportamento do consumidor operam sob o princípio de que as decisões de compra são essencialmente governadas pelo preço. Havendo igualdade em outros aspectos, quanto menor o preço, maior o volume de demanda. Além disso, no turismo quase que invariavelmente há um preço publicado para um produto ou serviço e um ou mais preços promocionais ou com descontos, a fim de se atender às exigências de determinados segmentos do mercado ou de lidar com a natural sazonalidade da demanda.

Grönroos (2004) afirma que, na maioria das empresas, clientes antigos pagam preços mais altos do que os novos. A principal razão para o efeito do adicional de preço pode ser o fato de clientes de longo tempo perceberem o valor oferecido pela empresa e realizarem economias de custo ao utilizarem o serviço de um prestador de serviço que conhecem bem. Para Corrêa e Caon (2002), o cliente tende a estabelecer, em sua mente, uma espécie de correlação entre o preço cobrado e a qualidade esperada do serviço. Preço é um aspecto do serviço que pode ser objetivamente avaliado, ranqueado e comparado. Muitas vezes o cliente tende a ranquear, em suas expectativas, a qualidade esperada de acordo com a sequência de ranqueamento de preço, como que assumindo que um serviço caro deve ser bom.

Segundo Machado, Machado e Holanda (2006), empresas enfrentam dificuldades para determinar o preço de seus produtos ou de seus serviços. Isto porque o preço sofre grande influência do mercado, levando em conta o poder aquisitivo da população, a qualidade, a oferta e as alternativas de escolha em função de suas preferências. O mercado requer que as empresas ofereçam serviços de qualidade com preços que o consumidor esteja disposto a pagar, e que devem ser suficientes para cobrir todos os custos e despesas, além de conter margem suficiente para o retorno sobre o 
capital aplicado. $\mathrm{O}$ entendimento da política de formação de preços é fundamental para que as organizações conheçam seus limites financeiros.

Hawkins, Mothersbaugh e Best (2007) acreditam que o preço seja um dos principais indicadores do valor que uma empresa entrega aos seus clientes, expressando monetariamente os benefícios que a empresa acredita que seus produtos ou serviços trazem para seus clientes. Para Sheth, Mittal e Newman (2001), os fatores limitadores da lealdade do cliente são inerentes ao próprio cliente, como, por exemplo, a busca por variedade, o envolvimento com o produto e a sensibilidade aos preços. Para Schiffman e Kanuk (2000), a maneira como um consumidor percebe um preço - alto, baixo, justo tem forte influência tanto nas intenções de compra (e de recompra), quanto na satisfação de compra. As percepções de injustiça nos preços afetam as percepções dos consumidores sobre o valor do produto e, em última análise, sua vontade de dar preferência a uma loja ou a um serviço.

De acordo com Santos e Botelho (2007), em situações onde as ofertas de serviços são pouco diferenciadas, com predominância de restrição orçamentária do consumidor, a variável preço acaba por ter importância significativa no processo de comunicação das vantagens relacionadas a essas ofertas. Comunicar adequadamente tais vantagens relacionadas ao preço torna-se fundamental no processo de decisão de compra do consumidor.

\subsection{QUALIDADE}

Medeiros (2009) afirma que a qualidade percebida muitas vezes permite que os clientes estejam dispostos a pagar mais por um produto do que pagariam pelo produto concorrente. Para Schiffman e Kanuk (2000), a qualidade percebida em serviços é mais difícil de ser avaliada pelos clientes do que a qualidade de produtos. A afirmativa baseia-se nas características diferentes dos serviços pelas suas particularidades que os diferenciam dos produtos, como sua intangibilidade e sua perecibilidade. Uma vez que a qualidade real dos serviços pode variar de um dia para o outro, de empregado para empregado e de cliente para cliente, as empresas tentam padronizar seus serviços a fim de oferecerem constância de qualidade. 
Segundo Fitzsimmons e Fitzsimmons (2005), em serviços, a avaliação da qualidade surge ao longo do processo de sua prestação, com a percepção do cliente a respeito podendo ser definida pela comparação entre a percepção do serviço prestado com as expectativas do serviço esperado. Quando se excedem as expectativas, o serviço é percebido como de qualidade excepcional. Hawkins, Mothersbaugh e Best (2007) afirmam que a qualidade percebida está relacionada ao preço, baseando-se no dito popular "o barato sai caro". Dizem que as garantias são sinal de qualidade, sendo que garantias mais longas geralmente sinalizam maior qualidade.

Mowen e Minor (2008) afirmam que a qualidade do produto é a avaliação completa dos clientes quanto à excelência do desempenho de um produto ou serviço. Os pesquisadores que investigam a área de prestação de serviços identificam cinco características em relação às quais os consumidores avaliam a qualidade do serviço, que podem ser vistas como sendo os atributos em relação aos quais os consumidores avaliam o desempenho geral dos serviços: tangibilidade, confiabilidade, tempo de resposta, segurança e empatia. Para Hawkins, Mothersbaugh e Best (2007), um dos aspectos de desempenho que melhor se correlaciona com a lealdade é a segurança, haja vista que um serviço já conhecido apresenta menores chances de falhas.

\subsection{SATISFAÇÃO DOS CLIENTES}

Segundo Grönroos (2004), os clientes ficam satisfeitos com a qualidade percebida desde que o sacrifício envolvido - preços e custos de relacionamento - não seja demasiadamente alto. Clientes satisfeitos podem tornar-se comprometidos com o fornecedor ou prestador de serviços porque confiam na outra parte ou porque estão contentes com o nível de sacrifício envolvido no relacionamento. Os clientes já existentes podem aumentar seu volume de negócios com o prestador de serviços e novos clientes serão atraídos para a organização.

Para Mowen e Minor (2008), a satisfação do consumidor é a atitude referente a um produto ou a um serviço após sua compra e uso. É um julgamento de avaliação pósescolha que resulta de uma seleção de compra específica de usá-la ou consumi-la. A grande satisfação é aparentemente sentida apenas quando o desempenho real é notavelmente superior ao desempenho esperado, e as atribuições que as pessoas fazem 
podem influenciar fortemente sua satisfação pós-compra em relação a um produto ou a um serviço.

A satisfação do consumidor é fonte de feedback sobre a qualidade das decisões de Marketing de uma organização, influenciando decisivamente a formação da intenção de compra futura do consumidor. Os consumidores satisfeitos costumam fazer comunicação "boca a boca" sobre uma experiência de compras positiva, afetando diretamente a viabilidade e a lucratividade de uma empresa (FREDERICO; ROBIC, 2006).

Gerar consumidores satisfeitos, e, portanto, vendas futuras exige que os consumidores continuem a acreditar que a marca ou o serviço atenda a suas necessidades e ofereça valor superior depois que eles os usam (HAWKINS; MOTHERSBAUGH; BEST, 2007). O cliente satisfeito não pedirá reparações, pois a transação em particular atendeu aos seus anseios. Todavia, o cliente meramente satisfeito não retornará, não se tornará um cliente fiel e, na maioria das vezes, não se transformará num entusiasmado vendedor do serviço. Para que isso aconteça, é necessário, no mínimo, que o cliente se veja como muito satisfeito (CORREA; CAON, 2002).

Para Sheth, Mittal e Newman (2001), os clientes estabelecidos já estão satisfeitos com a empresa. A não ser que exista um forte motivo para fazê-lo, os clientes estabelecidos provavelmente não trocarão seus fornecedores atuais. Se um concorrente deseja conquistar os clientes satisfeitos de uma empresa, deve oferecer um valor significativamente maior, seja na forma de preços mais baixos ou de um desempenho mais alto. Os autores afirmam que os custos dos clientes insatisfeitos são assombrosos: $96 \%$ dos clientes insatisfeitos não se queixam de atendentes rudes, mas $90 \%$ deles não voltam a comprar do mesmo fornecedor, ou contam sua história para pelo menos nove outras pessoas, e 13\% desses ex-clientes insatisfeitos contarão sua experiência para mais de 20 pessoas. A insatisfação, portanto, tem ampla divulgação e desestimula a lealdade.

No que diz respeito aos fornecedores de produtos de serviços de viagens e de turismo, é crescente a importância em se manter a lealdade de seus clientes, o que significa dar particular atenção à sua satisfação. Qualquer variação de baixa nesse grupo é questão de preocupação imediata, e suas respostas devem ser analisadas separadamente em todos os tipos de negócios do turismo (MIDDLETON, 2002). 


\subsection{LEALDADE}

Considera-se lealdade a compra e a preferência repetitiva por um produto - ou seja, "[...] um consumidor com uma atitude altamente relativa e alto grau de preferência repetido seria definido como fiel” (SCHIFFMAN; KANUK, 2000, p. 158). A lealdade em relação a um serviço pode surgir por meio de um desempenho tão acima do esperado que encante o cliente. Ela é provável em situações de serviço que envolvam encontros interpessoais extensos. Pesquisas sobre serviços também descobriram que a lealdade pode surgir a partir do conforto do consumidor. O conforto do consumidor é um estado psicológico em que a ansiedade do consumidor em relação a um serviço foi abrandada, e ele se sente tranquilo, calmo e sem preocupações em relação aos encontros de serviços e a um fornecedor específico (HAWKINS; MOTHERSBAUGH; BEST, 2007).

O Marketing de relacionamento envolve atividades destinadas a desenvolver ligações economicamente eficazes de longo prazo entre uma organização e seus clientes para o benefício de ambas as partes. As empresas de serviço podem usar uma diversidade de estratégias para manter e para melhorar as relações, entre elas estratégias básicas como o tratamento justo dos clientes, a oferta de ampliações nos serviços e o tratamento de cada cliente como se fosse particularmente importante. Programas de usuários frequentes são também muito usados como tática para recompensar a lealdade do cliente e para construir uma relação de longa duração (CROCCO; GIOIA, 2005).

A retenção de clientes já conquistados propicia melhor resultado financeiro e a garantia de lucros crescentes. A chave para o sucesso em lealdade é o profundo conhecimento dos clientes, de suas necessidades, de seus desejos e de como o produto e o serviço oferecido pela empresa podem agregar maior valor (CAMPOS, 2009).

Para Mowen e Minor (2008), a lealdade a uma marca ou a um serviço - de hospedagem, por exemplo - está intimamente ligada à satisfação do consumidor e ao seu comportamento de reclamação. A lealdade se dá pelo grau em que um consumidor mantém uma atitude positiva em relação à marca, estabelece um compromisso com ela e pretende continuar comprando-a no futuro. Ela está diretamente influenciada pela satisfação ou pela insatisfação com a marca acumulada ao longo do tempo, bem como pelas percepções de qualidade do produto ou do serviço que está sendo oferecido. 
Mowen e Minor (2008) mencionam que os consumidores leais estão além da satisfação e até mesmo da preferência duradoura por uma marca ou por um tipo de serviço, e que esses consumidores são defensores determinados da marca ou do serviço até mesmo em situações onde as contraofertas dos concorrentes tentam seduzi-los. Somente clientes muito satisfeitos apresentam um alto índice de recompra e uma propensão à comunicação "boca a boca" positiva. É importante surpreender os clientes de tal maneira que suas percepções da qualidade sejam satisfatórias o suficiente para reforçar sua lealdade e fazê-los recomprar (GRÖNROOS, 2004).

\section{METODOLOGIA}

A presente pesquisa se restringe ao estudo das pousadas localizadas no continente na cidade fluminense de Angra dos Reis, não tendo sido consideradas aquelas situadas na Ilha Grande e nas demais ilhas do município. Também se restringiu ao estudo de pousadas, não se levando em consideração outros meios de hospedagem como hotéis, resorts e albergues.

Ela se divide em duas partes, sendo a primeira uma pesquisa de campo qualitativa, de caráter exploratório. De acordo com Gil (2007), o objetivo principal desta é o aprimoramento de idéias. Já a segunda etapa consistiu de pesquisa com abordagem quantitativa, obedecendo ao paradigma clássico que postula a existência de uma realidade externa a ser examinada com objetividade, por meio da aplicação de métodos quantitativos (TERENCE; ESCRIVÃO FILHO, 2006). Malhotra (2006, p. 182) classificou este tipo de pesquisa como descritiva-conclusiva, porque “[...] tem como principal objetivo a descrição de algo - normalmente características ou funções do mercado". Adotou-se um levantamento do tipo survey, definido como tipo de pesquisa que emprega um questionário estruturado como instrumento de coleta, aplicado a uma amostra de uma população, e destinado a coletar-lhe informações.

\subsection{ETAPA QUALITATIVA}

A pesquisa qualitativa proporciona melhor visão e compreensão de um problema. Ela o explora com poucas ideias preconcebidas sobre o resultado dessa 
investigação. Além de defini-lo e desenvolver uma abordagem, a pesquisa qualitativa também é apropriada ao se enfrentar uma situação de incerteza, como quando os resultados conclusivos diferem das expectativas. Ela pode fornecer julgamentos antes ou depois dos fatos (MALHOTRA, 2006). Para Zouain e Vieira (2005), pesquisa qualitativa é basicamente aquela que busca entender um fenômeno específico em profundidade. Ao invés de estatísticas, de regras e de outras generalizações, a pesquisa qualitativa busca trabalhar com descrições, com comparações e com interpretações. Nela, o pesquisador é o instrumento de coleta e de análise dos dados.

Nesta fase, foram realizadas 10 entrevistas diretas com o apoio de questionário semiestruturado - ou seja, com questões de livre resposta - com hóspedes brasileiros de diferentes pousadas de Angra dos Reis. Todas as entrevistas foram integralmente gravadas, transcritas e posteriormente analisadas. A avaliação das transcrições se deu por meio da análise de conteúdo, que forneceu subsídios para a etapa quantitativa da pesquisa.

\subsection{ETAPA QUANTITATIVA}

Segundo Malhotra (2006), a pesquisa que quantifica os dados busca uma evidência conclusiva, que é baseada em amostras grandes e representativas e, de alguma forma, aplica análise estatística. Contrastando com a pesquisa qualitativa, as descobertas da pesquisa quantitativa podem ser tratadas como conclusivas e utilizadas para recomendar um curso de ação final.

O processo de coleta desta pesquisa foi desenvolvido por meio de questionário estruturado autoadministrado com questões fechadas, desenvolvido tomando-se por base, além dos postulados teóricos, os resultados encontrados na análise de conteúdo da etapa qualitativa. Inicialmente, ele foi aplicado à amostra-piloto em 30 hóspedes para verificar sua eficácia, tendo-se definido que não seria necessário que sofresse alterações. A amostra final contou com 316 observações oriundas de hóspedes de pousadas de Angra dos Reis, sendo 30 referentes ao teste-piloto e 286 coletadas após este.

O período da coleta foi o trimestre setembro-novembro de 2009, com as abordagens diretas dos pesquisadores aos pesquisados tendo sido realizadas dentro dos estabelecimentos, com prévia autorização dos meios de hospedagem. Os dados foram 
tabulados e tratados estatisticamente, por meio de análise de regressão logística binária, com o auxílio do software SPSS v.13.

\section{ANÁLISE DOS RESULTADOS}

Esse tópico trata das análises realizadas e dos respectivos resultados obtidos. Optou-se por manter-lhes a sequência conforme a pesquisa foi realizada primeiramente tratou-se da etapa qualitativa, de onde se extraíram subsídios para a condução da análise quantitativa, dividida em análise descritiva e análise da regressão logística binária. Por fim, as hipóteses da pesquisa foram abordadas e analisadas.

\subsection{ETAPA QUALITATIVA - ANÁLISE DE CONTEÚDO}

A análise de conteúdo é uma técnica que, quando quantitativamente orientada, implica que medidas padronizadas sejam aplicadas a unidades metricamente definidas, e que estas sejam usadas para caracterizar e comparar documentos. Quando utilizada qualitativamente, é uma técnica de pesquisa para a descrição objetiva e sistemática do conteúdo manifesto da comunicação (ZOUAIN; VIEIRA, 2005).

As entrevistas tiveram, como objetivo, verificar a lealdade dos hóspedes em relação às pousadas do município de Angra dos Reis. Os relatos foram categorizados e analisados conforme as etapas previstas pela metodologia da análise de conteúdo que, todavia, não serão aqui apresentadas tendo em vista limitações de espaço.

Nesta análise, verificou-se que os turistas não consideraram o risco de compra de um serviço como influenciador na decisão antes da sua utilização, como afirmou um dos entrevistados: "Nós optamos por essa [pousada] porque pareceu ser mais aconchegante, uma paisagem melhor, mais bonita, mais bem localizada". A opinião dos entrevistados revelou que eles não julgaram o preço como fator relevante na escolha de compra de um serviço de hospedagem: "Não, não levei em questão preço não... foi até melhor. O preço está igual a outras...". A prerrogativa pode ser reforçada por outro entrevistado: "Com uma vista dessa, o preço "tá" até bom demais... Justo. Justo". 
Ao serem questionados sobre a qualidade percebida em relação a atendimento, limpeza, conforto, infraestrutura e serviços oferecidos, os hóspedes relataram que a qualidade dos serviços prestados foi proporcional ao esperado:

É, eu acho bem claro. Eles são bem prestativos também. Eles fazem o serviço até que não deveriam às vezes; eles excedem, né? Prá dar conforto ao cliente... Ah, é boa, excelente também... Tudo muito bem limpo... Excelente também. Tudo limpo. A gente achou tudo excelente... É bom, né? O atendimento também é muito bom. $\mathrm{O}$ atendimento é primordial, né?

Os entrevistados relataram enfaticamente que a satisfação, bem como suas expectativas, foram atendidas e até superadas, como afirmou uma hóspede: "É, eu fiquei satisfeita, satisfeitíssima. Eles atendem às nossas expectativas bem... Muito bom... Ah, com certeza. Pelo menos nessa [pousada] aqui a gente ficou bem satisfeito. A gente já ficou em outras também, mas deixaram um pouco a desejar”.

Notou-se que a opinião da hóspede não é pontual, e ganhou reforço com a afirmação de um casal, que mencionou: “[...] a infraestrutura boa, o atendimento, os anfitriões são bem receptivos, bem corteses, gentis, então de início você já pretende voltar, já se sente acolhida, aconchegante no ambiente, então é isso".

A pesquisa qualitativa mostrou que o nível de intenção de lealdade dos entrevistados foi consideravelmente alto: "Com certeza... Vamos voltar a nos hospedar aqui."; "Voltaria, sei lá... todo final de semana... Claro. Como já voltei, né? Com certeza."; "Vamos voltar e nos hospedar aqui."; "Eu, voltando a Angra, vai ser aqui."; "Eu tenho tempo, eu tenho dinheiro, eu tenho vontade de viajar, voltaria com certeza.".

\subsection{ETAPA QUANTITATIVA}

A etapa quantitativa, conforme apontado anteriormente, incorpora, em sua estrutura analítica, não apenas os achados teóricos obtidos na revisão da literatura, mas também parte dos resultados obtidos na análise qualitativa. Desta forma, o presente modelo matemático fora desenvolvido pelos próprios autores.

\subsubsection{Análise descritiva}

A amostra de 316 casos restringiu-se a turistas brasileiros com mais de 18 anos de idade, sendo que $75 \%$ deles tinham entre 26 e 55 anos. A divisão entre homens e 
mulheres foi igualitária, e todos haviam permanecido por mais de uma noite na pousada. Os solteiros somaram $47 \%$ e os casados, 33\%; $42 \%$ eram graduados e $17 \%$ pósgraduados; $45 \%$ tinham renda superior a $\mathrm{R} \$ 4.000,00$ e $19 \%$ tinham renda entre $\mathrm{R} \$$ $3.000,00$ e $\mathrm{R} \$ 4.000,00 ; 46 \%$ visitavam a cidade com uma frequência de quatro a cinco vezes ao ano, e apenas $2 \%$ estavam lá pela primeira vez.

A pesquisa levantou informações sobre suas percepções no que tange ao risco da escolha, ao preço pago, à qualidade e à satisfação, além de sua tendência à lealdade.

\subsubsection{Etapa Quantitativa - Análise da Regressão Logística Binária}

O Quadro 1 detalha as hipóteses levantadas, testadas pelo modelo de regressão logística.

QUADRO 1 - HIPÓTESES INICIAIS DO MODELO

\begin{tabular}{|c|c|l|}
\hline \multicolumn{3}{|c|}{ HIPÓTESES } \\
\hline H1 & PREÇO1 & $\begin{array}{l}\text { O julgamento do preço exerce influência sobre a intenção de lealdade do } \\
\text { turista. }\end{array}$ \\
\hline H2 & PREÇO2 & $\begin{array}{l}\text { A percepção de justiça em relação ao preço pago, comparado ao preço de } \\
\text { outras pousadas, exerce influência sobre a intenção de lealdade do turista. }\end{array}$ \\
\hline H3 & ATEND1 & $\begin{array}{l}\text { Um bom atendimento exerce influência sobre a intenção de lealdade do } \\
\text { turista. }\end{array}$ \\
\hline H4 & INFRA1 & $\begin{array}{l}\text { Uma infraestrutura adequada exerce influência sobre a intenção de lealdade } \\
\text { do turista. }\end{array}$ \\
\hline H5 & ATEND3 & $\begin{array}{l}\text { O tempo de preenchimento da ficha de registro exerce influência sobre a } \\
\text { intenção de lealdade do turista. }\end{array}$ \\
\hline H6 & SATISF1 & $\begin{array}{l}\text { O julgamento das expectativas em relação ao grau de satisfação para com a } \\
\text { pousada exerce influência sobre a intenção de lealdade do turista. }\end{array}$ \\
\hline H7 & RECOM1 & $\begin{array}{l}\text { A recomendação da pousada para amigos ou para familiares exerce } \\
\text { influência sobre a intenção de lealdade do turista. }\end{array}$ \\
\hline H8 & INTLEAL & $\begin{array}{l}\text { O uso de camisa, boné, sacola ou de artigos relacionados com o nome da } \\
\text { pousada exerce influência sobre a intenção de lealdade do turista. }\end{array}$ \\
\hline
\end{tabular}

FONTE: ELABORAÇÃO PRÓPRIA.

Para Dias Filho e Corrar (2007), a regressão logística binária busca explicar ou predizer valores de uma variável em função de valores conhecidos de outras variáveis. Todavia, sua principal particularidade diz respeito ao fato de a variável dependente ser dicotômica, ou seja, binária, ou, ainda, uma variável dummy. Azevedo (1997) reforça a premissa ao mencionar que a regressão logística é frequentemente usada nos casos em que a variável dependente é binária, isto é, quando aceita apenas dois níveis de respostas como, por exemplo, sim ou não, solvente ou insolvente, doente ou não doente, leal ou não leal, além de outras possibilidades. Dias Filho e Corrar (2007) afirmam que esse 
ferramental estatístico tem, por objetivo, estimar a probabilidade de ocorrência de determinado evento ou de que um fenômeno venha a se enquadrar nessa ou naquela categoria.

Como método de avaliação, empregou-se o método Forward LR que é amplamente utilizado em tratamento de dados com regressão logística. Nele, constrói-se a equação de regressão logística, adicionando-se sequencialmente as variáveis. Além disso, empregam-se estimativas de razão de verossimilhança para determinar a variável que será adicionada à equação de regressão.

$\mathrm{Na}$ modelagem de regressão logística do presente trabalho adotou-se, como variável dependente, a intenção de lealdade do turista à pousada por ele visitada, admitindo-se, como respostas à situação, "LEAL" e "NÃO LEAL". As variáveis independentes são referentes às hipóteses levantadas.

Quando a constante é inscrita no modelo, 241 turistas de 316 entrevistados - ou seja, aproximadamente 76,3\% - apresentaram intenções de lealdade (ver Quadro 2). Ou seja, caso fosse solicitado que se apontassem os turistas que teriam intenções de retornar à pousada em que se hospedaram, este apontamento ao acaso corretamente alcançaria quase $76,3 \%$, considerando o modelo com apenas intercepto.

QUADRO 2 - CLASSIFICAÇÃO

\begin{tabular}{|c|c|c|c|c|c|}
\hline & & & & Prognóstico & \\
\hline & & & & ALP & Porcentagem \\
\hline & & & LEAL (1) & NÃO LEAL (2) & correta \\
\hline Passo 0 & $\begin{array}{l}\text { LEALP } \\
\text { Porcenta }\end{array}$ & $\begin{array}{l}\text { LEAL (1) } \\
\text { NÃO LEAL (2) }\end{array}$ & $\begin{array}{c}241 \\
75\end{array}$ & $\begin{array}{l}0 \\
0\end{array}$ & $\begin{array}{c}100,0 \\
0 \\
76,3\end{array}$ \\
\hline
\end{tabular}

FONTE: ELABORAÇÃO PRÓPRIA.

O Quadro 3 confirma que apenas a constante foi considerada no modelo, sendo exibido o resultado do teste de Wald. O teste de Wald é utilizado para avaliar se o parâmetro é estatisticamente significativo, bem como para verificar se o parâmetro B é igual a zero. Para Dias Filho e Corrar (2007), o teste se propõe a aferir o grau de significância de cada coeficiente da equação logística, inclusive a constante. Em outras palavras, os autores afirmam que o mecanismo tem, por finalidade, verificar se cada parâmetro estimado é significativamente diferente de zero. Obtendo-se significância 
estatística (parâmetro "Sig." ou "p"), rejeita-se a hipótese nula de que o intercepto seja zero.

QUADRO 3 - VARIÁVEIS DA EQUAČ̃̃

\begin{tabular}{|c|c|c|c|c|c|c|}
\hline & B & S.E. & Wald & Df & Sig. & $\operatorname{Exp}(B)$ \\
\hline Passo 0 Constante & $-1,167$ & 0,132 & 77,940 & 1 & 0,000 & 0,311 \\
\hline
\end{tabular}

FONTE: ELABORAÇÃO PRÓPRIA.

Assim,

$\operatorname{Logit}(\mathrm{Y}=1)=-1,167$

$\mathrm{P}(\mathrm{Y}=1) /[1-\mathrm{P}(\mathrm{Y}=1)]=\mathrm{e}-1,167=0,311$

Considerando o modelo apenas com intercepto, o impacto do intercepto sobre a chance é 0,311 .

O Quadro 4 apresenta os resultados do teste Omnibus, também chamado de teste de qui-quadrado ou Model Chi-Square, composto de quatro passos. Seu objetivo é avaliar a consistência do modelo como um todo e também verificar a hipótese nula de que todos os coeficientes da equação são nulos. No quarto passo (passo 4), onde o modelo encontra-se refinado, com a inclusão separada de cada variável, verifica-se que ele se revela consistente, e rejeita-se a hipótese nula de que todos os coeficientes sejam iguais a zero. A argumentação se baseia em Dias Filho e Corrar (2007), que defendem que tais valores devam apresentar significância estatística (Sig.), além de o valor de quiquadrado apresentar capacidade preditiva do modelo.

QUADRO 4 - TESTE OMNIBUS DO MODELO DE COEFICIENTES

\begin{tabular}{|cc|c|c|c|}
\hline & & $\begin{array}{c}\text { Qui- } \\
\text { quadrado }\end{array}$ & Graus de Liberdade & Sig. \\
\hline Passo 1 & Passo & 156,640 & 1 & 0,000 \\
& Bloco & 156,640 & 1 & 0,000 \\
& Modelo & 156,640 & 1 & 0,000 \\
\hline Passo 2 & Passo & 42,610 & 1 & 0,000 \\
& Bloco & 199,249 & 2 & 0,000 \\
& Modelo & 199,249 & 2 & 0,000 \\
\hline Passo 3 & Passo & 5,349 & 1 & 0,021 \\
& Bloco & 204,598 & 3 & 0,000 \\
& Modelo & 204,598 & 3 & 0,000 \\
\hline Passo 4 & Passo & 4,433 & 1 & 0,035 \\
& Bloco & 209,031 & 4 & 0,000 \\
& Modelo & 209,031 & 4 & 0,000 \\
\hline
\end{tabular}

FONTE: ELABORAÇÃO PRÓPRIA. 
O Quadro 5 apresenta outros indicadores que também contribuem para avaliar o desempenho geral do modelo. Os coeficientes atestam que, à medida que novas variáveis são inseridas no modelo, melhora a bondade de ajustamento, já que a estatística -2LL (Log likelihood) exibe sucessivas reduções até o passo 4. O modelo do passo 4 é o melhor, pois é aquele que exibe melhor ajustamento e menor valor de -2LL. À medida que o-2LL diminui, o erro de predição experimenta redução.

QUADRO 5 - SUMÁRIO DO MODELO

\begin{tabular}{|c|c|c|c|}
\hline Passos & -2 Log likelihood & Cox \& Snell R Square & Nagelkerke R Square \\
\hline 1 & 189,694 & 0,391 & 0,587 \\
2 & 147,084 & 0,468 & 0,702 \\
3 & 141,735 & 0,477 & 0,716 \\
4 & 137,303 & 0,484 & 0,727 \\
\hline
\end{tabular}

FONTE: ELABORAÇÃO PRÓPRIA.

Simultaneamente, constata-se que as pseudoestatísticas de R2 de Cox e Snell e Nagelkerke aumentam de estágio para estágio, atingindo maior patamar na fase 4. O R2 de Cox e Snell situou-se no patamar de 48,4\%, ao passo que o R2 de Nagelkerke ficou em $72,7 \%$. As duas estatísticas são muito razoáveis. De acordo com os preceitos de Dias Filho e Corrar (2007), a pseudo-estatística de R2 de Cox e Snell indica que 48,4\% das variações ocorridas no $\log$ da razão de chance são explicadas pelo conjunto de variáveis independentes. Já a medida Nagelkerke é uma versão adaptada da medida de Cox e Snell para fornecer valores entre 0 e 1 . Dessa maneira, pode-se concluir que o modelo é capaz de explicar 72,7\% das variações registradas na variável dependente - ou seja, nas intenções de lealdade do turista.

O Quadro 6 mostra que, dos 75 entrevistados que efetivamente não estariam dispostos a retornar à pousada visitada, o modelo previu corretamente $80 \%$ deles $(60$ entrevistados), falhando em relação à previsão de $20 \%$ deles (15 entrevistados). Quanto aos demais 241 entrevistados - ou seja, os que estavam efetivamente estavam dispostos a retornar à pousada - o modelo previu corretamente 97,1\% deles (234 acertos dentre 241 possíveis). 


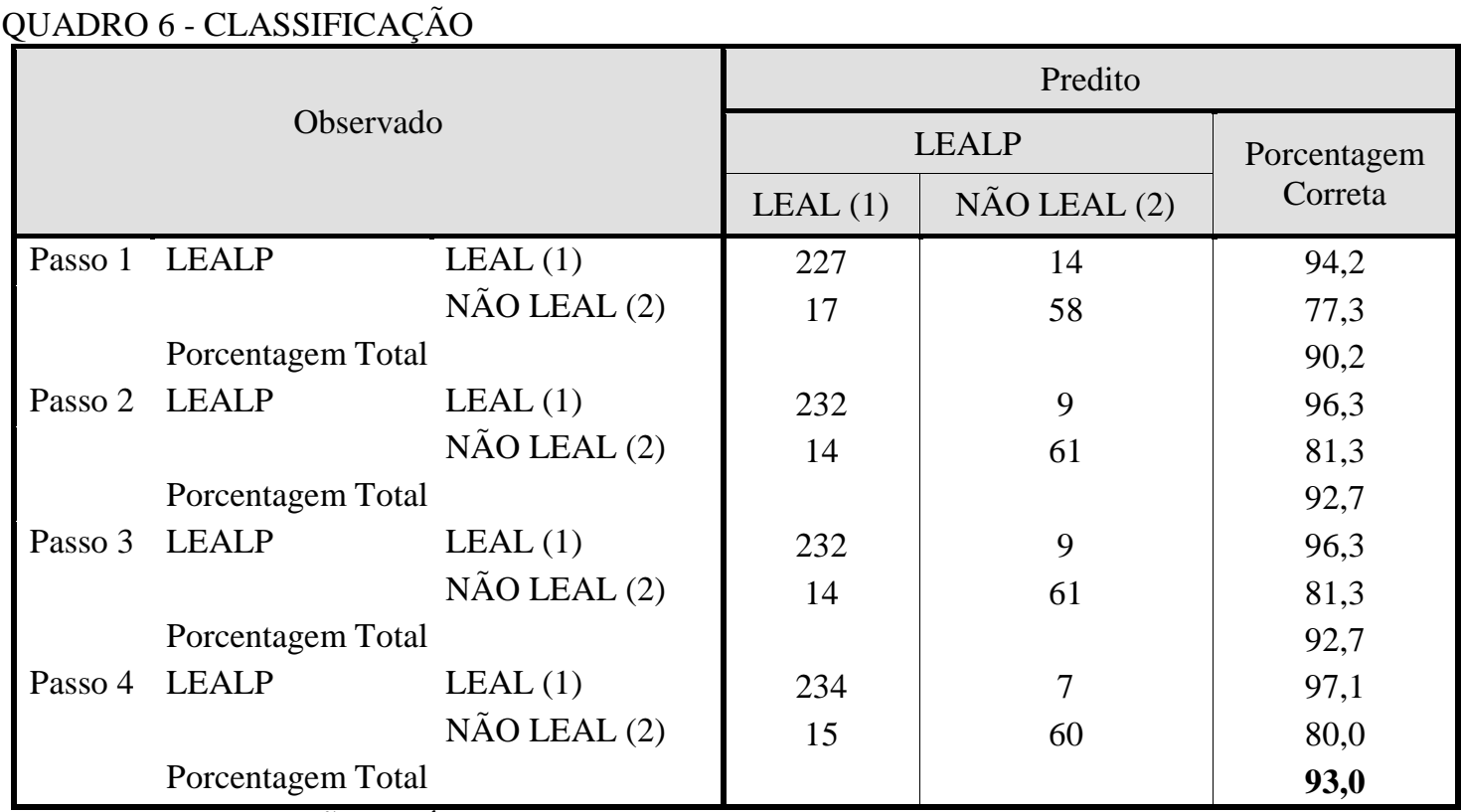

FONTE: ELABORAÇÃO PRÓPRIA.

Por outro lado, o modelo classificou equivocadamente como se não tivessem intenção de se hospedar novamente na pousada visitada cerca de 2,9\% (sete erros dentre 241 possíveis) dos respondentes que tinham efetiva intenção de fazê-lo. Em termos agregados, o modelo previu, com acerto, 93\% - ou seja, 60 acertos na indicação contrária de lealdade, acrescidos de 234 acertos na indicação favorável, contra 316 possibilidades.

Os testes estatísticos realizados até então demonstraram que o modelo pode ser empregado na estimativa de probabilidade de um turista retornar a uma pousada de Angra dos Reis. Dessa forma, lança-se mão da estatística Wald, de modo a se verificar se cada variável preditora encontrada realmente pode ser empregada como estimadora de probabilidade. O teste Wald verifica a hipótese nula de que o coeficiente seja igual a zero, o que significaria constatar a ineficiência da variável explicativa em predizer a variável dependente. Para rejeitar esta hipótese, a probabilidade deve ser inferior a 0,05 de significância.

No passo 4, todos os coeficientes se revelaram como importantes e possuidores de habilidade preditiva. O Quadro 7, de classificação de variáveis, mostra que quatro variáveis independentes são estatisticamente significativas na explicação das intenções de lealdade do turista: INFRA1; ATEND3; RECOM1; INTLEAL. Seus coeficientes de regressão logística apresentam significância estatística, conforme indicado pelo teste de Wald. 
QUADRO 7 - CLASSIFICAÇÃO

\begin{tabular}{|cl|c|c|c|c|c|c|}
\hline & & B & S.E. & Wald & Df & Sig. & Exp(B) \\
\hline Passo 1 & RECOM1 & $-2,111$ & 0,250 & 71,196 & 1 & 0,000 & 0,121 \\
& Constante & 6,707 & 0,929 & 52,115 & 1 & 0,000 & 818 \\
Passo 2 & INFRA1 & $-1,488$ & 0,263 & 31,931 & 1 & 0,000 & 0,226 \\
& RECOM1 & $-1,819$ & 0,261 & 48,680 & 1 & 0,000 & 0,162 \\
& Constante & 10,821 & 1,365 & 62,840 & 1 & 0,000 & 50081 \\
Passo 3 & INFRA1 & $-1,466$ & 0,277 & 27,961 & 1 & 0,000 & 0,231 \\
& ATEND3 &,- 641 & 0,273 & 5,507 & 1 & 0,019 & 0,527 \\
& RECOM1 & $-1,761$ & 0,267 & 43,641 & 1 & 0,000 & 0,172 \\
& Constante & 12,950 & 1,783 & 52,754 & 1 & 0,000 & 420951 \\
Passo 4 & INFRA1 & $-1,432$ & 0,279 & 26,313 & 1 & 0,000 & 0,239 \\
& ATEND3 &,- 605 & 0,279 & 4,705 & 1 & 0,030 & 0,546 \\
& RECOM1 & $-1,717$ & 0,275 & 38,994 & 1 & 0,000 & 0,180 \\
& INTLEAL &,- 411 & 0,197 & 4,326 & 1 & 0,038 & 0,663 \\
& Constante & 13,705 & 1,953 & 49,244 & 1 & 0,000 & 895399 \\
\hline
\end{tabular}

FONTE: ELABORAÇÃO PRÓPRIA.

Os coeficientes (B) do Quadro 7 são interpretados da seguinte forma: quanto maior sua magnitude, maior a probabilidade de o cliente retornar à pousada (ou o contrário, dependendo do sinal que precede a variável).

A equação de regressão logística pode ser expressa da seguinte forma:

$\mathrm{B}=13,705-1,432 * \mathrm{X} 1-0,605 * \mathrm{X} 2-1,717 * \mathrm{X} 3-0,411 * \mathrm{X} 4$.

Para fins de compreensão, considera-se a seguinte notação:

INFRA1: X1

ATEND3: X2

RECOM1: X3

INTLEAL: X4

\subsection{ANÁLISE DAS HIPÓTESES}

A análise das hipóteses formuladas foi elaborada a partir dos resultados apresentados no Quadro 7, que levaram à equação do modelo apresentado no item anterior.

O modelo estatístico classificou todos os turistas entrevistados com probabilidade de retorno à pousada entre 0 e 1, ou seja, de $0 \%$ a 100\%. Os turistas com probabilidade acima de $50 \%$ foram classificados como propensos à lealdade, enquanto os abaixo desse valor foram classificados como turistas em condições normais. Os 
turistas que ficaram em torno de $50 \%$ são os que apresentaram maior incerteza acerca de seu comportamento. O Quadro 8 apresenta a situação de validação das hipóteses do modelo.

QUADRO 8 - SITUAÇÃO DE VALIDAÇÃO DAS HIPÓTESES DO MODELO

\begin{tabular}{|c|c|l|c|}
\hline H1 & PREÇO1 & $\begin{array}{l}\text { O julgamento do preço exerce influência sobre a intenção de } \\
\text { lealdade do turista. }\end{array}$ & REJEITADA \\
\hline H2 & PREÇO2 & $\begin{array}{l}\text { A percepção de justiça em relação ao preço pago, comparado } \\
\text { ao preço de outras pousadas, exerce influência sobre a intenção } \\
\text { de lealdade do turista. }\end{array}$ & REJEITADA \\
\hline H3 & ATEND1 & $\begin{array}{l}\text { Um bom atendimento exerce influência sobre a intenção de } \\
\text { lealdade do turista. }\end{array}$ & REJEITADA \\
\hline H4 & INFRA1 & $\begin{array}{l}\text { Uma infraestrutura adequada exerce influência sobre a } \\
\text { intenção de lealdade do turista. }\end{array}$ & ACEITA \\
\hline H5 & ATEND3 & $\begin{array}{l}\text { O tempo de preenchimento da ficha de registro exerce } \\
\text { influência sobre a intenção de lealdade do turista. }\end{array}$ & ACEITA \\
\hline H6 & SATISF1 & $\begin{array}{l}\text { O julgamento das expectativas em relação ao grau de } \\
\text { satisfação com a pousada exerce influência sobre a intenção de } \\
\text { lealdade do turista. }\end{array}$ & REJEITADA \\
\hline H7 & RECOM1 & $\begin{array}{l}\text { A recomendação da pousada para amigos ou familiares exerce } \\
\text { influência sobre a intenção de lealdade do turista. }\end{array}$ & ACEITA \\
\hline H8 & INTLEAL & $\begin{array}{l}\text { O uso de camisa, boné, sacola ou artigos relacionados com o } \\
\text { nome da pousada exerce influência sobre a intenção de } \\
\text { lealdade do turista. }\end{array}$ & ACEITA \\
\hline
\end{tabular}

FONTE: ELABORAÇÃO PRÓPRIA.

Foram rejeitadas as hipóteses $\mathrm{H} 1$ e $\mathrm{H} 2$, que tratam do julgamento do preço pago pela hospedagem e de sua respectiva influência nas intenções de lealdade à pousada. Isso sugere que o fator preço, embora exerça influência direta nas decisões de compra, conforme cita a literatura, não é elemento preponderante na intenção de lealdade dos turistas. Por outro lado, a não aceitação dessas hipóteses foi corroborada pelos depoimentos: "Com certeza... Vamos voltar a nos hospedar aqui."; "Voltaria, sei lá... todo final de semana... Claro. Como já voltei, né? Com certeza"; "Vamos voltar e nos hospedar aqui"; "Eu, voltando a Angra, vai ser aqui"; "Eu tenho tempo, eu tenho dinheiro, eu tenho vontade de viajar, voltaria com certeza". Certamente esses achados ajudam a justificar a prerrogativa de que o cliente satisfeito - e leal - está disposto a pagar preços premium pelos serviços de seu interesse.

A não aceitação das hipóteses também pode ter sofrido influência direta do poder aquisitivo dos turistas estudados, que eram relativamente altos (SCHIFFMAN; KANUK, 2000; SHETH; MITTAL; NEWMAN， 2001; GRÖNROOS， 2004; 
FITZSIMMONS; FITZSIMMONS, 2005; HAWKINS; MOTHERSBAUGH; BEST, 2007; MOWEN; MINOR, 2008).

Em relação ao atendimento (H3), verificou-se que ele não explicou a influência exercida sobre as intenções de lealdade do turista. A não aceitação de tal hipótese refutou a teoria que prega haver correlação entre bom atendimento e lealdade. É possível interpretar este achado pela ótica de que, em muitos estabelecimentos de hospedagem, o bom atendimento é confundido com impessoalidade. No caso, o público nacional preferiria contato mais próximo, diferentemente do público estrangeiro, especialmente norte-americanos e europeus.

A confirmação de $\mathrm{H} 4$ indicou que uma infraestrutura adequada exerce influência sobre a intenção de lealdade do turista. Isso poderia ser explicado pelo fato de, em seus momentos de lazer, o hóspede normalmente procurar por conforto e por opções de entretenimento. $O$ tratamento estatístico indicou que, na percepção do turista, uma infraestrutura inadequada apresenta score igual a e-1,432 =0,239. Ou seja, o cálculo $[100 *(0,239-1)=76,1]$ mostrou que uma infraestrutura inadequada diminui em 0,239 vezes - ou em $76,1 \%$ - a chance de o turista se tornar leal ao meio de hospedagem.

A hipótese H5 demonstrou que o tempo de preenchimento da ficha de registro obrigatório exerce influência na lealdade dos turistas em relação ao meio de hospedagem. Na opinião do turista, tal hipótese apresenta score de e-0,605 =0,546. Ou seja, a simples perda de tempo com o preenchimento de fichas de registro, obrigatórias em check ins, diminui em 0,546 vezes - ou em $45,4 \%$ - a chance de o turista apresentar intenções de lealdade ao meio de hospedagem, conforme o cálculo $[100 *(0,546-1)=$ $45,4]$.

A hipótese H6 demonstrou que o julgamento das expectativas em relação ao grau de satisfação não exerceu poder preditivo frente à lealdade do turista. Embora tal medida seja um forte indicativo de satisfação, e apesar de a satisfação ser classificada na literatura como um dos antecedentes da lealdade, a hipótese foi rejeitada. Nesta circunstância, cabe destacar os estudos de Mittal e Lassar (1998), que mostraram relações desconexas entre satisfação e lealdade: eles expandiram o estudo realizado por Maddox (1981), com o argumento de que a satisfação e a insatisfação não se unem em um continuum, pois a insatisfação é uma variável dominante. Também observaram que, enquanto a insatisfação é quase uma garantia de troca de fornecedores, a satisfação, por 
sua vez, não assegura lealdade. Dessa forma, o estudo confirmou tal fato, demonstrando que a satisfação, neste contexto, não apresenta poder preditivo para as intenções de lealdade.

A predisposição à recomendação da pousada para amigos e parentes, segundo o estudo, apresenta-se como um forte indicativo das intenções de lealdade, representado pela aceitação de H7. A não ocorrência da predisposição à recomendação diminui a chance de lealdade em 0,180 vezes, ou seja, em $82 \%$, conforme o cálculo [100*(0,180$1)=82]$. O achado corrobora as teorias que relacionam comunicação "boca a boca" com intenções de lealdade. Em outras palavras, para recomendar a localidade o turista precisa estar encantado - ou seja, mais que satisfeito.

Por fim, H8 demonstrou que o hóspede comprometido com a pousada, assumindo a predisposição a usar camisas, bonés, sacolas e artigos promocionais com o nome da pousada, é um hóspede com indicativo de lealdade. O comprometimento do cliente para com a organização se apresenta como uma variável preditora da lealdade, com score igual a e-0,411 =0,663. Ou seja, a não ocorrência de tal predisposição diminui em 0,633 vezes, ou em $33,7 \%$, a chance de o turista se tornar leal ao meio de hospedagem, conforme o cálculo $[100 *(0,663-1)=33,7]$.

\section{CONCLUSÃO}

O objetivo da presente pesquisa foi verificar se os elementos preditores (risco percebido, preço, qualidade e satisfação do consumidor) influenciavam na intenção de lealdade dos turistas que se hospedavam em pousadas da cidade fluminense de Angra dos Reis.

A pesquisa qualitativa mostrou-se adequada para utilização em estudos que englobam a dinâmica e a estrutura da lealdade. Já a etapa quantitativa permitiu mensurar, de fato, as variáveis preditoras da lealdade nesse contexto. Dentre as variáveis analisadas, e a partir dos resultados obtidos, pôde-se observar que a infraestrutura, a comunicação "boca a boca", o atendimento e o comprometimento com a pousada foram as variáveis que apresentaram maior preponderância sobre a intenção 
de lealdade. Devem ser, portanto, os aspectos centrais para a adoção de estratégias que visem à manutenção dos clientes.

Recomenda-se, com base na aceitação de H7, que o gestor de pousadas da região priorize investimentos que fortaleçam a infraestrutura do estabelecimento. Ou seja, além da oferta de ambiente limpo, seguro, agradável e confortável, o gestor deve se preocupar com serviços e com opções de entretenimento. Este aspecto se revelou importante, especialmente considerando-se que o município de Angra dos Reis, muito visitado para o desfrute das belezas naturais associadas às praias, possui alto índice pluviométrico. Nesta circunstância, o meio de hospedagem deve estar preparado para ofertar entretenimento mesmo em dias de chuva. O problema da demora no check in pode ser facilmente resolvido adotando-se práticas já consagradas, como, por exemplo, o check in on line, feito via Internet no momento da reserva. Cabe aqui destacar a importância na eficácia desse tipo de atendimento, haja vista que, na chegada, o hóspede normalmente anseia por se livrar da burocracia necessária e iniciar, de fato, o desfrute de sua estada.

A pesquisa demonstrou que tanto o comprometimento do cliente para com o estabelecimento quanto sua predisposição em recomendar a pousada apresentaram relação direta com a predição das intenções de lealdade. Assim sendo, presume-se que ações que visem a estreitar e a intensificar o relacionamento com o cliente, além de torná-lo um comprometido vendedor dos serviços de hospedagem, ampliam significativamente as chances de lealdade.

Como toda pesquisa, algumas limitações foram encontradas, o que, por vezes, proporciona resultado ou análise menos detalhados. Para este estudo, algumas destas restrições se devem ao alcance limitado, já que não envolveu todas as pousadas existentes no município de Angra dos Reis. Outra limitação consistiu na indisposição de turistas em responder a questões em seu momento de desfrute hedônico. O trabalho apresenta, ainda, limitação de ordem metodológica, representada pela adoção de amostra por conveniência, o que impede sua generalização.

Recomenda-se, para futuras pesquisas, a replicação do estudo com pousadas em outras localidades e, em um segundo momento, a aplicação do modelo em outros meios de hospedagem, tais como hotéis e resorts, visando a lhe conferir maior abrangência. Propõe-se, ainda, a avaliação das hipóteses por meio de outros ferramentais estatísticos, 
com vistas a ampliar a compreensão da temática lealdade no complexo contexto turístico.

\section{REFERÊNCIAS}

AZEVEDO, P. R. M. Modelos de Regressão Linear. Natal: Editora da UFRN, 1997.

CAMPOS, A. A. Lealdade Gerando Lucros: Conheça Melhor os seus hóspedes. Disponível em: <http://www.abih.com.br/principal/artigos. Php?Id=8>. Acesso em: 13/11/2009.

DIAS FILHO, J. M.; CORRAR, L. J. Regressão Logística. In. CORRAR, L. J.; PAULO, E.; DIAS FILHO, J. M. D. (Orgs.) Análise Multivariada - para os cursos de administração, ciências contábeis e economia. São Paulo: Atlas, 2007, cap. 2.

CORRÊA, H. L; CAON. M. Gestão de Serviços: Lucratividade por Meio de Operações e de Satisfação dos Clientes. São Paulo: Atlas, 2002.

CROCCO, L.; GIOIA, R. M. Decisões de Marketing: Os 4 Ps. Coleção de Marketing v. 2, 1. ed. São Paulo: Saraiva, 2005.

FARIAS, S. A. de; KOVACS, M. H. Esforço do Consumidor, Estratégias de Redução do Risco Percebido e Satisfação: Proposição de um Esquema Teórico para o Comércio Eletrônico. In: ENCONTRO ANPAD, 30, 2006, Salvador/BA: ANPAD, 2006. Anais... CD-ROM.

FITZSIMMONS, J. A.; FITZSIMMONS, M. J. Administração de Serviços: operações, estratégia e tecnologia da informação. 4. ed. Porto Alegre: Bookman, 2005.

FREDERICO, E.; ROBIC, A. R. Estudo dos Fatores Determinantes da Satisfação do Consumidor com Vestuário Infantil. In: ENCONTRO ANPAD, 30, 2006, Salvador/BA: ANPAD, 2006. Anais... CD-ROM.

GIL, A. C. Como Elaborar Projetos de Pesquisas. São Paulo: Atlas, 2007.

GRÖNROOS, C. Marketing: gerenciamento e serviços. Rio de Janeiro: Elsevier, 2004.

HAWKINS, D. I.; MOTHERSBAUGH, D. L.; BEST, R. J. Comportamento do Consumidor: Construindo a Estratégia de Marketing. 10. ed. Rio de Janeiro: Elsevier, 2007.

LOUREIRO, S.; GONZÁLEZ, F. The Importance of Quality, Satisfaction, Trust, and Image in Relation to Rural Tourist Loyalty. Journal of Travel \& Tourism Marketing, 25 (2), 117. 2008. 
MACHADO, M. A.; MACHADO, M. R.; HOLANDA, F. M. de A. Análise do Processo de Formação de Preços do Setor Hoteleiro da cidade de João Pessoa/PB: Um estudo Exploratório. In: ENCONTRO ANPAD, 30., 2006, Salvador/BA: ANPAD, 2006. Anais... CD-ROM.

MADDOX, R. N. Two-factor theory and consumer satisfaction: replication and extension. Journal of Consumer Research, v. 8, n. 1, p. 97-103, 1981.

MAlHOTRA, N. K. Pesquisa de Marketing: uma orientação aplicada. 4. ed. Porto Alegre: Bookman, 2006.

MEDEIROS, R. Empreendedorismo e Inovação: Criação e Desenvolvimento de Produtos e Serviços - Volume Único UFF. Rio de Janeiro: Neami, 2009.

MIDDLETON, V. T. C. Marketing de turismo: Teoria e prática. 3. ed. Rio de Janeiro: Campus, 2002.

MITTAL, B.; LASSAR, W. M. Why do customers switch? The dynamics of satisfaction. Journal of services Marketing, v. 12, n. 2/3, p. 177-195, 1998.

MOWEN, J. C.; MINOR, M. S. Comportamento do consumidor. 6. reimpr. São Paulo: Prentice Hall, 2008.

PEREIRA, L. H.; COBRA, M. H. N. Estratégias de Redução de Risco Percebido na Compra e no Consumo de Carne Bovina. In: ENCONTRO ANPAD, 30., 2006, Salvador/BA: ANPAD, 2006. Anais... CD-ROM.

SANTOS, J. H. F. dos; BOTELHO, D. Análise Comparativa de Preços: Estudo de Variáveis Influentes na Percepção de Vantagem de Compra, In: ENCONTRO ANPAD, 31., 2007, Rio de Janeiro/RJ: ANPAD, 2007. Anais... CD-ROM.

SCHIFFMAN, L. G.; KANUK, L. L. Comportamento do Consumidor. 6. ed. Rio de Janeiro: LTC, 2000.

SHETH, J. N.; MITTAL, B. I; NEWMAN, B. I. Comportamento do Cliente: Indo Além do Comportamento do Consumidor. São Paulo: Atlas, 2001.

TERENCE, A. C. F.; ESCRIVÃO FILHO, E. Abordagem quantitativa, qualitativa e a utilização da pesquisa-ação nos estudos organizacionais. In: ENCONTRO NACIONAL DE ENGENHARIA DE PRODUÇÃO, 26, 2006, Fortaleza/CE. Anais... CD-ROM.

ZOUAIN, D. M.; VIEIRA, M. M. F. Pesquisa Qualitativa em Administração: Teoria e Prática. V. 2, 1. ed. Rio de Janeiro: Ed. FGV, 2005.

Recebido em: 23-06-2012.

Aprovado em: 23-07-2012. 